\title{
Photo-Induced Room-Temperature Gas Sensing with a-IGZO Based Thin-Film Transistors Fabricated on Flexible Plastic Foil
}

\author{
Stefan Knobelspies ${ }^{1, *(\mathbb{C})}$, Benedikt Bierer ${ }^{2}$, Alwin Daus ${ }^{1}{ }^{10}$, , Alain Takabayashi ${ }^{1}$, \\ Giovanni Antonio Salvatore ${ }^{1}$ (10), Giuseppe Cantarella ${ }^{1}$ (D), Alvaro Ortiz Perez ${ }^{2}$, \\ Jürgen Wöllenstein ${ }^{2,3}$, Stefan Palzer 4 (iD and Gerhard Tröster ${ }^{1}$ (iD \\ 1 Electronics Laboratory, Swiss Federal Institute of Technology (ETH) Zürich, Gloriastrasse 35, \\ 8092 Zürich, Switzerland; dausa@ife.ee.ethz.ch (A.D.); talain@student.ethz.ch (A.T.); \\ giovanni.salvatore@ife.ee.ethz.ch (G.A.S.); giuseppe.cantarella@ife.ee.ethz.ch (G.C.); \\ troester@ife.ee.ethz.ch (G.T.) \\ 2 Laboratory for Gas Sensors, Department of Microsystems Engineering (IMTEK), University of Freiburg, \\ Freiburg, Germany; benedikt.bierer@imtek.uni-freiburg.de (B.B.); alvaro.ortiz.perez@imtek.de (A.O.P.); \\ juergen.woellenstein@imtek.uni-freiburg.de (J.W.) \\ 3 Fraunhofer Institute for Physical Measurement Techniques, Freiburg, Germany \\ 4 Department of Computer Science, Universidad Autónoma de Madrid, Francisco Tomás y Valiente 11, \\ 28049 Madrid, Spain; stefan.palzer@uam.es \\ * Correspondence: stefan.knobelspies@ife.ee.ethz.ch; Tel.: +41-44-632-2744
}

Received: 19 December 2017; Accepted: 23 January 2018; Published: 26 January 2018

\begin{abstract}
We present a gas sensitive thin-film transistor (TFT) based on an amorphous Indium-Gallium-Zinc-Oxide (a-IGZO) semiconductor as the sensing layer, which is fabricated on a free-standing flexible polyimide foil. The photo-induced sensor response to $\mathrm{NO}_{2}$ gas at room temperature and the cross-sensitivity to humidity are investigated. We combine the advantages of a transistor based sensor with flexible electronics technology to demonstrate the first flexible a-IGZO based gas sensitive TFT. Since flexible plastic substrates prohibit the use of high operating temperatures, the charge generation is promoted with the help of UV-light absorption, which ultimately triggers the reversible chemical reaction with the trace gas. Furthermore, the device fabrication process flow can be directly implemented in standard TFT technology, allowing for the parallel integration of the sensor and analog or logical circuits.
\end{abstract}

Keywords: a-IGZO; gas sensor; flexible electronics; thin-film transistor; $\mathrm{NO}_{2}$

\section{Introduction}

Health complications arising from urban air pollution are among the top ten causes of death in high-income countries [1]. Most pollutants originate from fuel combustion in either mobile sources, such as combustion-powered vehicles, or stationary sources, like power plants [1-3]. Several studies have demonstrated that, among the pollutants, nitrogen dioxide $\left(\mathrm{NO}_{2}\right)$ directly affects human health [4] by damaging DNA, or causing asthma [5] and other chronic pulmonary diseases [6]. The consequences of urban $\mathrm{NO}_{2}$ exposure contributed to an estimated 75,000 premature deaths throughout the European continent in 2012 [2]. Although the $\mathrm{NO}_{2}$ emission limits in leading markets have been progressively tightened, recent disclosures e.g., the Volkswagen diesel scandal, showed that the emissions of over half of on-road light-duty diesel vehicles exceed these certification limits [2,7].

As a direct result, the demand and interest in devices for health or environmental monitoring, such as smart wearable systems, have been growing rapidly. In this field, flexible electronics, e.g., sensors for UV-light [8], temperature [9] or gas $[10,11]$ are emerging. One particularly appealing 
application is chemical gas sensing, which may be achieved using sensors based on metal oxide (MOX) semiconductors. Due to their low cost and high robustness, they are among the top candidates as a functional layer [12] and several groups have demonstrated the use of MOX semiconductors for $\mathrm{NO}_{2}$ sensing $[13,14]$.

State-of-the-art MOX based gas sensors are used in resistive readout mode and usually require operation temperatures between $200^{\circ} \mathrm{C}$ and $400^{\circ} \mathrm{C}$. Crystalline Tin dioxide $\left(\mathrm{SnO}_{2}\right)$, Zinc oxide $(\mathrm{ZnO})$ and Titanium dioxide $\left(\mathrm{TiO}_{2}\right)$ are currently the most prominent materials, which account for about $70 \%$ of the overall MOX gas sensor applications [15]. Nowadays, one major research focus is the implementation of these materials into nano-sized structures, such as nanowires, nanobelts, nanorods or nanoparticles to increase the surface-to-volume ratio and therefore to increase the sensitivity [16]. Nevertheless, to achieve room-temperature operation and integration into wearable devices, new materials and different sensor structures need to be exploited. One alternative approach for chemical gas sensing with MOX semiconductors is the implementation into field effect transistors (FETs). The FET based gas sensor was presented in 1975, using a catalytically active gate material [17]. The observation that a shift in the electrical characteristics occurs due to polarization phenomena in the metal-semiconductor interface has led to a large number of different device types, usually produced in standard silicon technology [18]. Subsequent developments directly used the FET channel material as gas sensitive layer. The interaction between analyte and semiconductor leads to an electron transfer between them that changes the carrier concentration, mobility and semiconductor work function and ultimately results in a response of the transistor current [19]. Here, we utilize the recent developments in flexible thin-film transistor (TFT) technology [20] to fabricate a chemical sensor, whose channel material also acts as the gas sensitive layer. The integration of this gas sensor into a wearable device requires two key elements: mechanical flexibility and compatible fabrication processes of sensor and circuitry. Since flexible plastic substrates usually prohibit the use of high operating temperatures, we investigate the applicability of amorphous Indium-Gallium-Zinc-Oxide (a-IGZO) based TFTs as room temperature-operating gas sensors. In the field of flexible electronics, a-IGZO has received much attention due to its high electron mobility and compatibility with low temperature deposition processes [21]. Nevertheless, there exists just a few reports on a-IGZO gas sensors [22-26] that are based on a rigid substrate and resistive readout. As the interaction of the semiconductor with the trace gas relies on the availability and number of free charge carriers at the surface, UV-light can be used to generate electron-hole pairs, instead of traditional heating $[23,24,27]$. The gas sensor presented here shows sensitivity to $\mathrm{NO}_{2}$ in the ppm region with negligible hysteresis behavior. We perform a material analysis of the a-IGZO layer using X-ray diffraction (XRD), ultraviolet-visible (UV-Vis) spectroscopy, scanning electron microscopy (SEM) and atomic force microscopy (AFM), and relate the sensor behavior to its physical mechanisms. Finally, the cross-sensitivity to humidity is evaluated. The presented sensor with a compatible fabrication process to circuitry is paving the way for the implementation of a-IGZO based gas sensors in wearable applications.

\section{Experimental and Results}

\subsection{Fabrication}

The devices are fabricated on free-standing $50 \mu \mathrm{m}$ thick polyimide foil (Kapton E, DuPont, DA, USA) in a bottom gate inverted staggered configuration. The fabrication flow and the schematic device cross-section is displayed in Figure 1a. First, the substrate is cleaned in acetone and 2-propanol for $5 \mathrm{~min}$ each with the help of sonication. Subsequently, a $24 \mathrm{~h}$ bake out at $200{ }^{\circ} \mathrm{C}$ is performed to remove residual solvents. Afterwards, a $50 \mathrm{~nm}$ thick layer of $\mathrm{SiN}_{\mathrm{x}}$ is deposited on both sides of the substrate by plasma-enhanced chemical vapor deposition (PECVD) at $150{ }^{\circ} \mathrm{C}$ to inhibit further degassing and to promote the adhesion of the following layers. The gate metal consisting of $\mathrm{Ti} / \mathrm{Au} / \mathrm{Ti}(5 / 50 / 5 \mathrm{~nm})$ is electron beam evaporated and patterned by photolitography and lift-off. Then, a $20 \mathrm{~nm}$ thick $\mathrm{Al}_{2} \mathrm{O}_{3}$ insulator layer is grown by atomic layer deposition (ALD) at $150{ }^{\circ} \mathrm{C}$ followed by a $15 \mathrm{~nm}$ thick 
a-IGZO layer deposited by room temperature RF magnetron sputtering using an $\mathrm{InGaZnO}_{4}$ target. The semiconductor layer is structured into islands and gate vias are formed in the insulator both by wet chemical etching. Finally, the drain/source (Ti/Au 10/60 nm) contacts are deposited by electron beam evaporation and structured by photolitography and lift-off. Similarly to what presented for TFTs, readout systems (composed by analog and digital circuits) can also be realized with the same thin-film technology. Figure $1 \mathrm{~b}$ shows a sketch of the layout and a micrograph of a device after fabrication. A photograph of the fully fabricated flexible sample is presented in Figure 1c.

a)

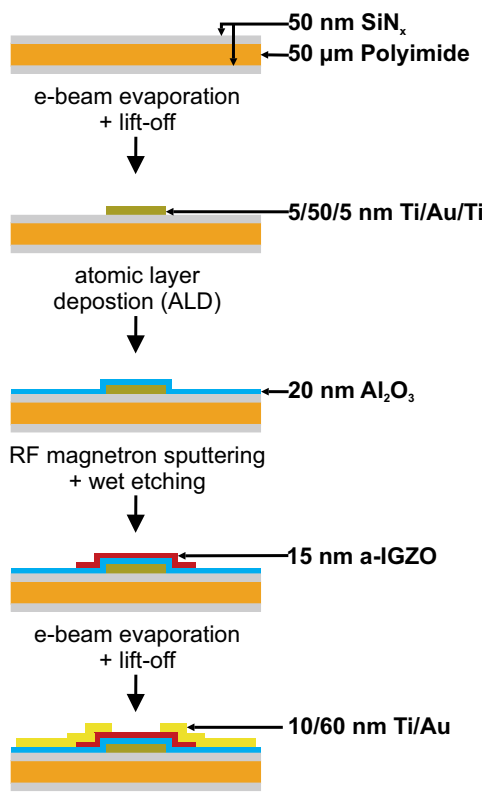

b)

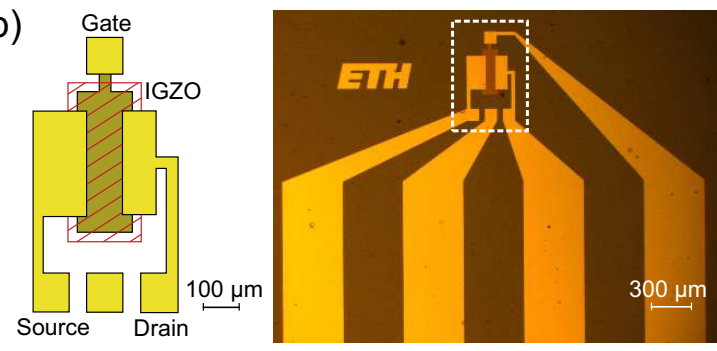

c)

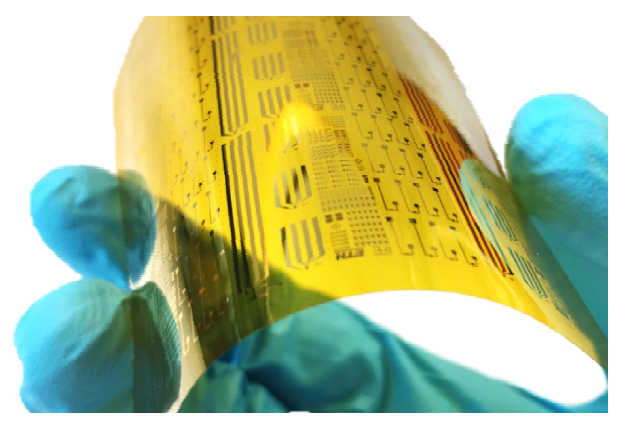

Figure 1. (a) schematic fabrication flow of the gas sensitive thin-film transistor (TFT) including the respective layer thicknesses. (b) layout of the TFT indicating the different layers and dimensions (left) and a macroscopic picture of the fabricated device (right). The TFT is highlighted with dashed lines.

(c) photograph of the fabricated sensors on the flexible polyimide substrate.

\subsection{Physical Properties and Sensing Mechanism}

The properties of the a-IGZO semiconductor layer are analyzed by UV-Vis absorption spectroscopy, an XRD measurement, SEM imaging and AFM.

Figure 2a shows the optical absorption spectrum of $15 \mathrm{~nm}$ thick a-IGZO. The layer is deposited on a quartz glass plate to avoid signal losses due to a highly absorbing polyimide substrate layer. The absorption value increases for light wavelengths smaller than the bandgap of $3.05 \mathrm{eV}$, which correlates to $406 \mathrm{~nm}$ [8]. To verify the amorphous structure of the RF-sputtered thin-film, an XRD measurement is presented in Figure 2b. Here, a $200 \mathrm{~nm}$ thick a-IGZO layer on quartz glass is used to increase the a-IGZO signal intensity and to obtain a well-known background signal. The first broad peak around 2 theta $=22$ degrees corresponds to the quartz glass substrate [28] and the plateau between 30 and 35 degrees indicates a-IGZO [29].

The surface topology of the semiconductor layer is studied using SEM and AFM imaging and is shown in Figure 2c,d, respectively. Both measurements are performed on the fabricated TFT gas sensors. As reported in our previous work, the semiconductor forms a homogeneous layer that conforms to the underlying material stack (i.e., polyimide, $\mathrm{SiN}_{\mathrm{x}}, \mathrm{Ti} / \mathrm{Au} / \mathrm{Ti}, \mathrm{Al}_{2} \mathrm{O}_{3}$ stack) and the visible grains are related to the wavy surface of the $\mathrm{SiN}_{\mathrm{x}}$ layer [30]. The average surface roughness determined from the AFM measurement is $4.727 \mathrm{~nm}$, thus increasing the surface to volume ratio, which is preferable for the sensor operation. Due to the absorption spectrum of the a-IGZO, a UV-LED 
with a peak wavelength of $375 \mathrm{~nm}$ is used to generate free charges in the semiconductor [23,31], which will ultimately trigger the reversible chemical reaction with the trace gas.
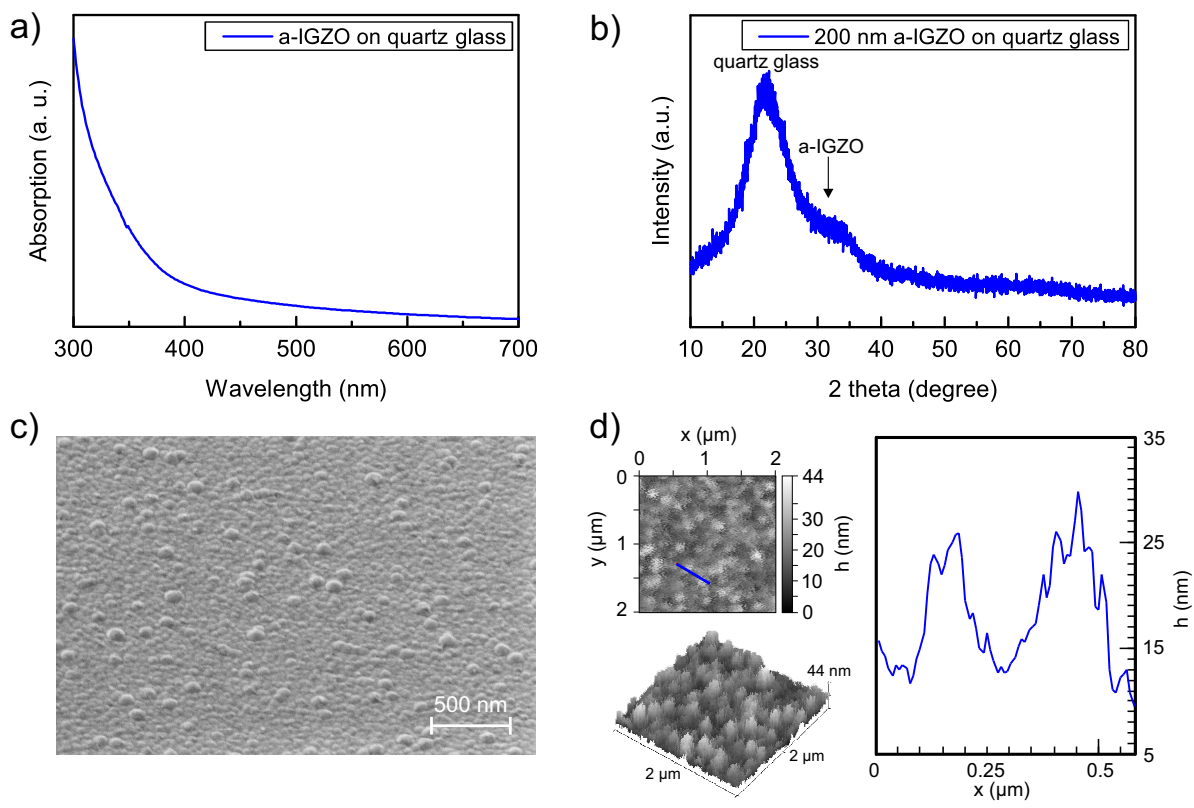

Figure 2. (a) ultraviolet-visible (UV-Vis) absorption spectra of $15 \mathrm{~nm}$ thick a-IGZO and (b) X-ray diffraction (XRD) of a $200 \mathrm{~nm}$ thick a-IGZO layer, both deposited on quartz glass. (c) scanning electron microscopy (SEM) image of the a-IGZO semiconductor layer; (d) atomic force microscopy (AFM) of the a-IGZO surface including the 2D and 3D height profile and a representative line profile. SEM and AFM imaging are performed on the fabricated TFT gas sensor.

First, the photo-generated electron-hole pairs are separated to the conduction and valence band, respectively. This increase in charge carriers leads to an increased transistor drain current $\mathrm{I}_{\mathrm{D}}$. As soon as the a-IGZO is in contact with the atmosphere, as shown in Figure 3a, the oxygen adsorbs at the semiconductor surface (Equation (1)), acting as an acceptor molecule and forming a back-channel depletion area. Due to the partial depletion, the $I_{D}$ decreases accordingly [32]:

$$
\mathrm{O}_{2}+\mathrm{e}^{-} \rightarrow \mathrm{O}_{2}^{-}{ }^{-} \text {(ads) }
$$

When $\mathrm{NO}_{2}$ enters the atmosphere, it also adsorbs at the semiconductor surface as presented in Figure $3 \mathrm{~b}$. By taking one negative charge from the conduction band, the $\mathrm{NO}_{2}$ chemisorbs as $\mathrm{NO}_{2}{ }^{-}$ (see Equation (2)) [33]. The electron affinity of $\mathrm{NO}_{2}$ is significantly higher compared to the one of $\mathrm{O}_{2}$ [34]. The back-channel depletion width will increase, which results in a decreased $\mathrm{I}_{\mathrm{D}}$. The change in $\mathrm{I}_{\mathrm{D}}$ correlates directly with the $\mathrm{NO}_{2}$ concentration, since the atmospheric $\mathrm{O}_{2}$ concentration can be considered constant:

$$
\mathrm{NO}_{2}+\mathrm{e}^{-} \rightarrow \mathrm{NO}_{2}^{-}{ }^{-} \text {ads). }
$$

Since a-IGZO is an n-type semiconductor, the reactions with $\mathrm{O}_{2}$ and $\mathrm{NO}_{2}$ will also occur in a attenuated form without UV-illumination due to free electrons in the conduction band. These surface mechanisms occur due to the homogeneous non-porous a-IGZO layer, as described in the conduction model for MOX gas sensors in [35]. A-IGZO based TFTs are known to be influenced by humidity [36]. Nevertheless, as already proposed for other metal oxide semiconductors [37] and shown in Figure 3c, photo-generated holes can recombine with the previously trapped electrons of $\mathrm{NO}_{2}$ promoting the desorption of the gas molecules (Equation (3)):

$$
\mathrm{NO}_{2}{ }^{-} \text {(ads) }+\mathrm{h}^{+}{ }_{\text {(photo-generated) }} \rightarrow \mathrm{NO}_{2}(\mathrm{~g}) .
$$


When $\mathrm{H}_{2} \mathrm{O}$ molecules adsorb at the metal-oxide surface, the free carrier concentration at the back-channel increases, which counteracts the depletion because charge is transferred between water molecules and the semiconductor surface (Equation (4)) [38]:

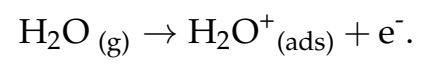

The interactions between semiconductor surface and gas molecules and the formation of a partially depleted channel are reported for zinc tin oxide TFTs and $\mathrm{H}_{2} \mathrm{O}$ [39], which is in agreement with the proposed mechanisms.
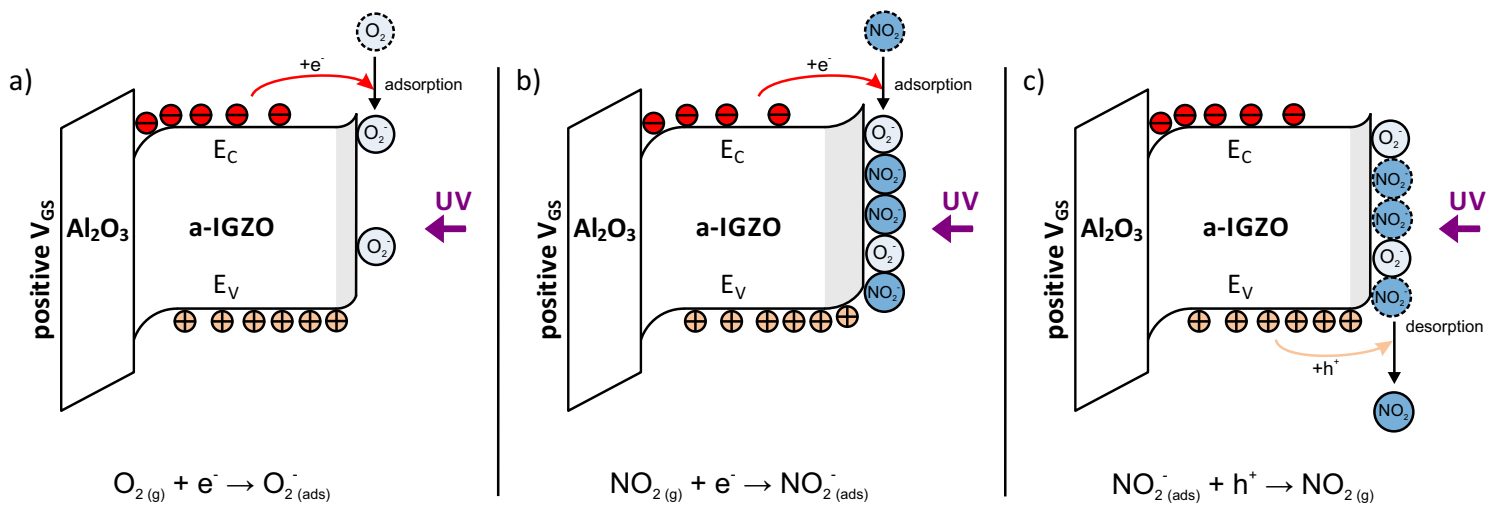

Figure 3. Schematic band diagram of the TFT sensing layer and gate insulator under UV-illumination and in contact with gas. Under illumination with UV-light, the generated electron-holes pairs are separated to the conduction and valence band, respectively. This results in an increased number of charge carriers thereby an increased transistor drain current $\left(\mathrm{I}_{\mathrm{D}}\right)$. (a) oxygen molecules from the atmosphere adsorb at the semiconductor surface acting as surface-acceptors and therefore forming a back-channel depletion as indicated in the band diagram. Due to this depletion region, the transistor $\mathrm{I}_{\mathrm{D}}$ decreases. (b) As soon as the $\mathrm{NO}_{2}$ comes in contact with the sensor, it also adsorbs at the surface acting as an electron-acceptor. The back channel depletion area will increase and the transistor $\mathrm{I}_{\mathrm{D}}$ decreases further. (c) After returning to normal atmosphere without $\mathrm{NO}_{2}$, the adsorbed $\mathrm{NO}_{2}{ }^{-}$ molecules desorb from the surface by the help of a positive charge from the semiconductor valence band. The back-channel depletion width and the $I_{D}$ return to the states described in (a).

\subsection{TFT Characterization and Gas Measurements}

The TFT sensor response is measured with a two channel source-measure unit (SMU, Agilent B2902A, CA, USA). Figure 4 shows the transfer $\left(I_{D}-V_{G S}\right)$ and output characteristics $\left(I_{D}-V_{D S}\right)$ of a TFT gas sensor under dark condition (initial status), under UV-light illumination and while exposed to UV-light and 5 ppm $\mathrm{NO}_{2}$ gas.

In the dark condition, the TFT has a threshold voltage of $\mathrm{V}_{\mathrm{Th}}=0.87 \mathrm{~V}$ and an effective saturation mobility of $\mu_{\text {sat }}=13.34 \mathrm{~cm}^{2} \mathrm{~V}^{-1} \mathrm{~s}^{-1}$. The sensor operating point is chosen in the saturation regime at a drain-source voltage $\mathrm{V}_{\mathrm{DS}}$ of $5 \mathrm{~V}$ and a gate-source voltage $\mathrm{V}_{\mathrm{GS}}$ of $0.8 \mathrm{~V}$. Due to the incident UV-light, the $\mathrm{V}_{\mathrm{Th}}$ and therefore the transfer characteristic are negatively shifted, as shown in Figure 4a and reported in [8]. In the presence of $\mathrm{NO}_{2}$, the transfer characteristic is shifted in a positive direction, resulting in a decreased $\mathrm{I}_{\mathrm{D}}$, as also shown in the output curves of Figure $4 \mathrm{c}$. The observations in the electrical characteristics are in agreement with our proposed sensing mechanism. 
a)

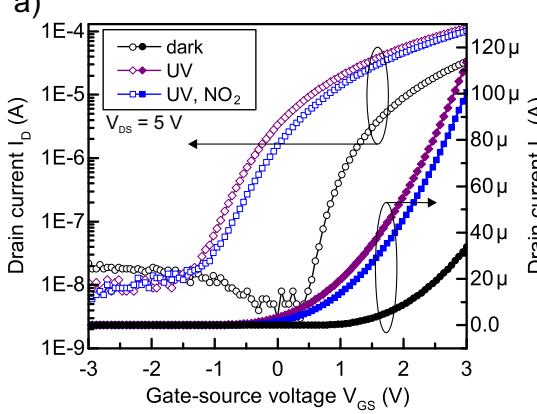

b)

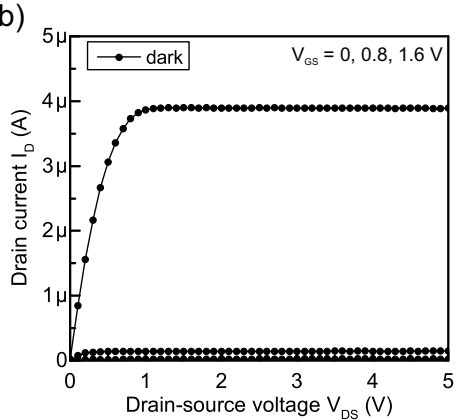

c)

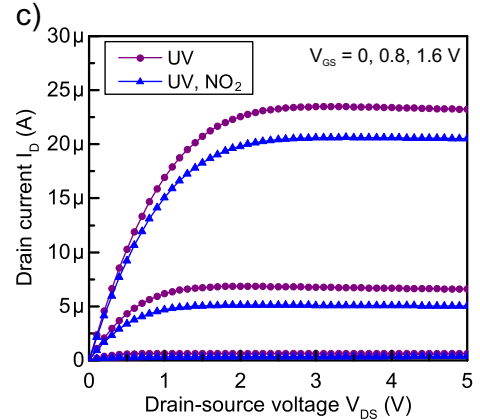

Figure 4. Electrical characteristics of the a-IGZO TFT $(\mathrm{W} / \mathrm{L}=280 \mu \mathrm{m} / 80 \mu \mathrm{m})$ gas sensor in dark condition, under UV-light illumination and while exposed to UV-light and $5 \mathrm{ppm} \mathrm{NO}_{2}$. For all measurements, the background oxygen was set to $20 \%$. The measurement under UV-light was performed after 2 min illumination. (a) transfer characteristics and (b,c) output characteristics.

The TFT sensor response is characterized in a custom-built laboratory apparatus, which allows for a automated simulation of various trace gas compounds and concentrations, including the relative humidity and background oxygen [40]. The time needed for a complete gas exchange inside the measurement chamber is estimated as $1.8 \mathrm{~min}$, which is neglected in further calculations and fitting procedures. The measurement setup and biasing scheme are schematically presented in Figure 5a. The $\mathrm{I}_{\mathrm{D}}$ of the TFT is used as the gas dependent sensor signal and the UV-intensity is set to $17 \mathrm{~mW} \cdot \mathrm{cm}^{-2}$. For all measurements, the $\mathrm{O}_{2}$ concentration is set to $20 \%$, which resembles atmospheric conditions. The raw $\mathrm{I}_{\mathrm{D}}$ signal at $2-5 \mathrm{ppm} \mathrm{NO} \mathrm{NO}_{2}$ at $20 \%$ oxygen, $0 \%$ relative humidity and room temperature is shown in Figure 5b. Compared to the TFT characteristic in Figure 4, the $\mathrm{I}_{\mathrm{D}}$ is significantly increased due to continuous UV-exposures over long periods of time and, as explained in Figure 3, the current decreases as soon as the sensor is in contact with the trace gas. We observe a drift in the sensor baseline that can be attributed to photo-induced charge trapping at oxygen vacancies within the a-IGZO or at the a-IGZO $/ \mathrm{Al}_{2} \mathrm{O}_{3}$ interface as reported in our previous work [8]. Nevertheless, this effect does not influence the reaction of analyte gas with the semiconductor surface. To analyze the dependence between gas concentration and sensor signal, the $I_{D}$ response is fitted with the exponential function $I(t)=A \cdot \exp p^{(-t / \psi)}+c$. The fits show an average $\mathrm{R}^{2}$-value of $0.9973 \pm 0.0013$. The extracted time constants $\tau$ for adsorption and desorption of $\mathrm{NO}_{2}$ are $\tau_{\text {adsorption }}=13.5 \pm 3.6 \mathrm{~min}$ and $\tau_{\text {desorption }}=50.2 \pm 2.9 \mathrm{~min}$. Figure $5 \mathrm{c}$ presents the normalized response of the fitted steady state values, which are sufficiently reached after 100 minutes by extrapolating the respective functions $I(t)$ to $\mathrm{t}=100 \mathrm{~min}$. The response to $\mathrm{NO}_{2}$ is defined by $I_{\text {Drain, }, 0} / I_{\text {Drain }, \mathrm{NO}_{2}}$. In the analyzed gas concentrations, we observe an almost hysteresis free change of $\mathrm{I}_{\mathrm{D}}$ in the range of $19 \%$ to $29 \%$. Even though one expects a logarithmic behavior, linear fitting can be applied in the analyzed $\mathrm{NO}_{2}$ range to estimate the sensitivity, resulting in a value of $3.47 \% / \mathrm{ppm}$. It is worth mentioning that the sensor response is quite slow, but, through exponential fitting, the gas concentration can already be estimated before reaching the steady state values. The response time of the sensor could be improved by inducing heat, e.g., by implementing a buried microheater structure, since the surface response of metal oxide based gas sensors to $\mathrm{NO}_{2}$ exposure is directly affected by temperature as shown for $\mathrm{Cu}(\mathrm{II}) \mathrm{O}$ in [14]. Furthermore, we evaluated the cross-sensitivity to humidity (defined by $I_{\text {Drain, } \mathrm{H}_{2} \mathrm{O}} / I_{\text {Drain, }, 0}$.) in the range of $0 \%$ to $50 \%$. The device shows an almost linear dependence (R-square $=0.984$ ) between relative humidity and the normalized $\mathrm{I}_{\mathrm{D}}$, as presented in Figure $5 \mathrm{~d}$. By linear fitting, as indicated by the dashed line, the cross-sensitivity yields a value of $0.17 \% /$ rel.hum.(\%). 
a)
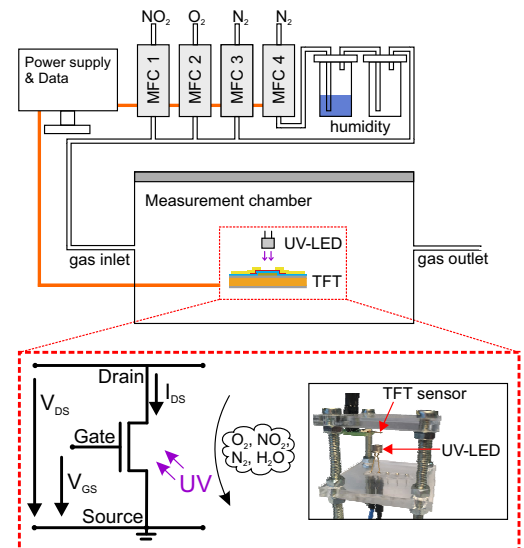

c)

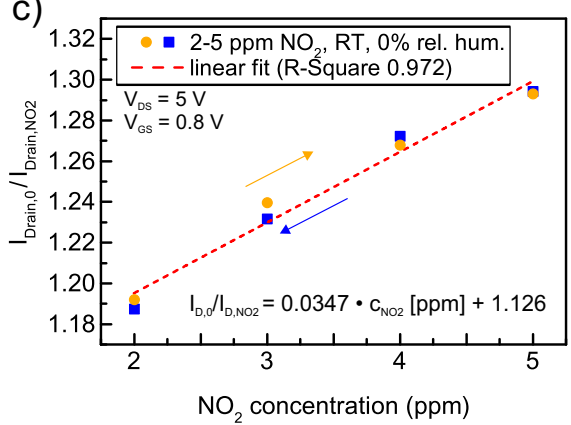

b)

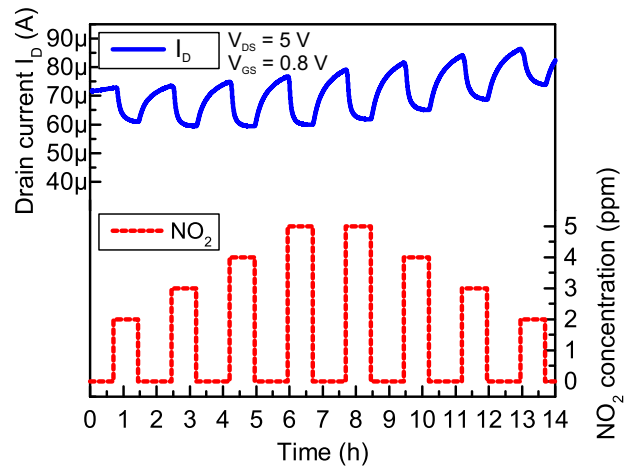

d) 1

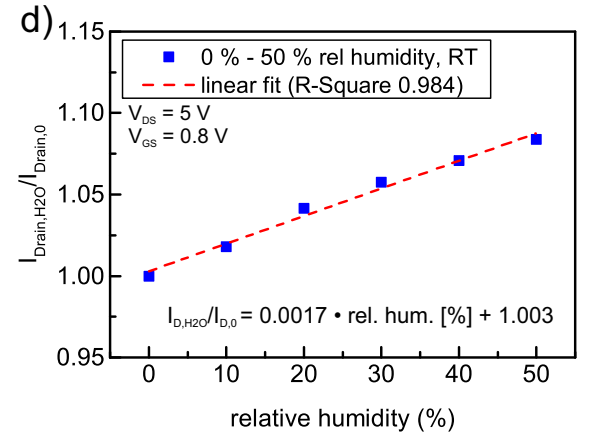

Figure 5. (a) schematic of the measurement setup. The desired gas mixture is prepared by four mass flow controllers (MFC 1-4), each connected to a different gas species. The relative humidity is changed by the ratio between dry (MFC 3) and wet (MFC 4) nitrogen. The TFT gas sensor, as well as the UV-light source are placed inside the measurement chamber (see photograph). The biasing and measurement scheme is presented in the inset; (b) $\mathrm{I}_{\mathrm{D}}$ raw signal to 2-5 ppm NO $\mathrm{N}_{2}$ with $20 \%$ background oxygen, $0 \%$ relative humidity at room temperature; (c) normalized sensor signal to $2-5 \mathrm{ppm} \mathrm{NO}_{2}$. The arrows indicate the sweep direction of the $\mathrm{NO}_{2}$ concentration; (d) cross-sensitivity to humidity ( $20 \%$ oxygen, RT) as normalized sensor signal.

\section{Conclusions}

We presented, for the first time, a photo-induced a-IGZO based gas sensitive TFT that operates at room temperature. The fabrication flow on a flexible free standing polyimide foil is compatible with state-of-the-art flexible TFT technology to allow the parallel integration of the gas sensor and readout circuits. The physical mechanisms, i.e., the photo-generation of free charge carriers and the resulting reactions between semiconductor surface and oxygen, $\mathrm{NO}_{2}$ and humidity are explained by means of a band diagram and chemical reaction equations and the principle is confirmed by experiments. The sensor shows an almost hysteresis free response of $3.47 \% / \mathrm{ppm}$ to $\mathrm{NO}_{2}$ in the investigated range of $2-5 \mathrm{ppm}$ with $20 \%$ background oxygen at room temperature. Furthermore, a nearly linear cross-sensitivity to humidity is observed between $0 \%$ and $50 \%$ relative humidity, which is small compared to the $\mathrm{NO}_{2}$ response. Previous studies showed that our TFT technology allows a stable operation of the TFTs while bent to a tensile radius down to $6 \mathrm{~mm}$ without significant changes in the electrical characteristics and the response to UV-light [8]. Thus, future research should be focused on the gas sensing performance under mechanical bending. Further aspects that have to be considered are the influences of small temperature variations within the room temperature range and the correction of the baseline-drift. 
Acknowledgments: Stefan Knobelspies acknowledges funding by grants from the Swiss National Science Foundation (SNSF), through the project WISDOM, under Grant 200021E-160347/1. Benedikt Bierer acknowledges funding from the Graduate School decentralized, sustainable energy systems (DENE). Stefan Palzer acknowledges funding from the Community of Madrid under Grant 2016-T1/AMB-1695. The authors thank M. Stiefel from EMPA for the help with SEM imaging. Furthermore, we thank C. Hierold and S. Eberle for the help with the gas measurements.

Author Contributions: Stefan Knobelspies conceived and designed the experiments; Stefan Knobelspies fabricated the devices; Stefan Knobelspies and Alwin Daus performed the material analysis; Stefan Knobelspies and Alain Takabayashi performed the electrical characterization; Stefan Knobelspies, Benedikt Bierer and Alvaro Ortiz Perez performed the gas measurements; Stefan Knobelspies and Alwin Daus analyzed the data; Jürgen Wöllenstein, Stefan Palzer and Gerhard Tröster supervised the project. Stefan Knobelspies wrote the paper; and all authors contributed with discussions and feedback on the manuscript and the project.

Conflicts of Interest: The authors declare no conflict of interest.

\section{References}

1. WHO. Global Health Risks: Mortality and burden of disease attributable to selected major risks. Bull. World Health Organ. 2009, 87, 646, doi:10.2471/BLT.09.070565.

2. Schmidt, C.W. Beyond a One-Time Scandal. Environ. Health Perspect. 2016, 124, 19-22, doi:10.1289/ehp.124-A19.

3. Magno, M.; Jelicic, V.; Chikkadi, K.; Roman, C.; Hierold, C.; Bilas, V.; Benini, L. Low-Power Gas Sensing using Carbon Nanotubes in Wearable Devices. IEEE Sens. J. 2016, 16, 8329-8337, doi:10.1109/JSEN.2016.2606087.

4. Kim, K.H.; Jahan, S.A.; Kabir, E. A review on human health perspective of air pollution with respect to allergies and asthma. Environ. Int. 2013, 59, 41-52, doi:10.1016/j.envint.2013.05.007.

5. Sunyer, J.; Spix, C.; Quénel, P.; Ponce-de-León, A.; Pönka, A.; Barumandzadeh, T.; Touloumi, G.; Bacharova, L.; Wojtyniak, B.; Vonk, J.; et al. Urban air pollution and emergency admissions for asthma in four European cities: The APHEA Project. Thorax 1997, 52, 760-765, doi:10.1136/thx.52.9.760.

6. Andersen, Z.J.; Hvidberg, M.; Jensen, S.S.; Ketzel, M.; Loft, S.; Sørensen, M.; Tjønneland, A.; Overvad, K.; Raaschou-Nielsen, O. Chronic obstructive pulmonary disease and long-term exposure to traffic-related air pollution: A cohort study. Am. J. Respir. Crit. Care Med. 2011, 183, 455-461, doi:10.1164/rccm.201006-0937OC.

7. Anenberg, S.C.; Miller, J.; Minjares, R.; Du, L.; Henze, D.K.; Lacey, F.; Malley, C.S.; Emberson, L.; Franco, V.; Klimont, Z.; Heyes, C. Impacts and mitigation of excess diesel-related NOx emissions in 11 major vehicle markets. Nature 2017, 545, 467-471, doi:10.1038/nature22086.

8. Knobelspies, S.; Daus, A.; Cantarella, G.; Petti, L.; Münzenrieder, N.; Tröster, G.; Salvatore, G.A. Flexible a-IGZO Phototransistor for Instantaneous and Cumulative UV-Exposure Monitoring for Skin Health. Adv. Electron. Mater. 2016, 2, 1600273, doi:10.1002/aelm.201600273.

9. Kim, D.-H.; Lu, N.; Ma, R.; Kim, Y.-S.; Kim, R.-H.; Wang, S.; Wu, J.; Won, S.M.; Tao, H.; Islam, A.; et al. Epidermal Electronics. Science 2011, 333, 838-843, doi:10.1126/science.1206157.

10. Chung, M.G.; Kim, D.H.; Seo, D.K.; Kim, T.; Im, H.U.; Lee, H.M.; Yoo, J.B.; Hong, S.H.; Kang, T.J.; Kim, Y.H. Flexible hydrogen sensors using graphene with palladium nanoparticle decoration. Sens. Actuators B Chem. 2012, 169, 387-392, doi:10.1016/j.snb.2012.05.031.

11. Zheng, Z.Q.; Yao, J.D.; Wang, B.; Yang, G.W. Light-controlling , flexible and transparent ethanol gas sensor based on ZnO nanoparticles for wearable devices. Sci. Rep. 2015, 5, 11070, doi:10.1038/srep11070.

12. Liu, X.; Cheng, S.; Liu, H.; Hu, S.; Zhang, D.; Ning, H. A Survey on Gas Sensing Technology. Sensors 2012, 12, 9635-9665, doi:10.3390/s120709635.

13. Wetchakun, K.; Samerjai, T.; Tamaekong, N.; Liewhiran, C.; Siriwong, C.; Kruefu, V.; Wisitsoraat, A.; Tuantranont, A.; Phanichphant, S. Semiconducting metal oxides as sensors for environmentally hazardous gases. Sens. Actuators B Chem. 2011, 160, 580-591, doi:10.1016/j.snb.2011.08.032.

14. Kneer, J.; Wöllenstein, J.; Palzer, S. Manipulating the gas-surface interaction between copper (II) oxide and mono-nitrogen oxides using temperature. Sens. Actuators B Chem. 2016, 229, 57-62, doi:10.1016/j.snb.016.01.104.

15. Neri, G. First Fifty Years of Chemoresistive Gas Sensors. Chemosensors 2015, 3, 1-20, doi:10.3390/chemosensors3010001.

16. Choi, K.J.; Jang, H.W. One-dimensional oxide nanostructures as gas-sensing materials: Review and issues. Sensors 2010, 10, 4083-4099, doi:10.3390/s100404083. 
17. Bergveld, P. The impact of MOSFET-based sensors. Sens. Actuators 1985, 8, 109-127, doi:10.1016/0250-6874(85)87009-8.

18. Lundström, I. Why bother about gas-sensitive field-effect devices? Sens. Actuators A Phys. 1996, 56, 75-82, doi:10.1016/0924-4247(96)01286-1.

19. Korotcenkov, G. Handbook of Gas Sensor Materials; Springer: New York, NY, USA, 2014.

20. Petti, L.; Münzenrieder, N.; Vogt, C.; Faber, H.; Büthe, L.; Cantarella, G.; Bottacchi, F.; Anthopoulos, T.D.; Tröster, G. Metal Oxide Semiconductor Thin-Film Transistors for Flexible Electronics. Appl. Phys. Rev. 2016, 3, 1-57, doi:10.1063/1.4953034.

21. Nomura, K.; Ohta, H.; Takagi, A.; Kamiya, T.; Hirano, M.; Hosono, H. Room-temperature fabrication of transparent flexible thin-film transistors using amorphous oxide semiconductors. Nature 2004, 432, 488-492, doi:10.1038/nature03090.

22. Yang, D.J.; Whitfield, G.C.; Cho, N.G.; Cho, P.S.; Kim, I.D.; Saltsburg, H.M.; Tuller, H.L. Amorphous InGaZnO 4 films: Gas sensor response and stability. Sens. Actuators B Chem. 2012, 171, 1166-1171, doi:10.1016/j.snb.2012.06.057.

23. Jaisutti, R.; Kim, J.; Park, S.K.; Kim, Y.-H. Low-Temperature Photochemically Activated Amorphous Indium-Gallium-Zinc Oxide for Highly Stable Room-Temperature Gas Sensors. ACS Appl. Mater. Interfaces 2016, 8, 20192-20199, doi:10.1021/acsami.6b05724.

24. Wu, C.; Jiang, G.; Chang, K.; Deng, Z.; Li, Y.; Chen, K.-L.; Jeng, C.-C. Analysis of the Sensing Properties of a Highly Stable and Reproducible Ozone Gas Sensor Based on Amorphous In-Ga-Zn-O Thin Film. Sensors 2018, 18, 163, doi:10.3390/s18010163.

25. Wu, C.; Jiang, G.; Chang, K.; Deng, Z.; Chen, K. Amorphous indium gallium zinc oxide thin film-based ozone sensors. IEEE Sens. Proc. 2015, doi:10.1109/ICSENS.2015.7370578.

26. Chen, H.; Jiang, W.; Zhu, L.; Yao, Y. Amorphous In-Ga-Zn-O Powder with High Gas Selectivity towards Wide Range Concentration of $\mathrm{C}_{2} \mathrm{H}_{5} \mathrm{OH}$. Sensors 2017, 17, 1203, doi:10.3390/s17061203.

27. Lin, C.-W.; Huang, K.-L.; Chang, K.-W.; Chen, J.-H.; Chen, K.-L.; Wu, C.-H. Ultraviolet photodetector and gas sensor based on amorphous In-Ga-Zn-O film. Thin Solid Films 2016, 618, 100-103, doi:10.1016/j.tsf.2016.05.013.

28. Qi, L.; Hu, Z.; Li, W.; Qin, X.; Du, G.; Han, W.; Shi, W. Influence of substrate on the growth of microcrystalline silicon thin films deposited by plasma enhanced chemical vapor deposition. Mater. Sci. Semicond. Process. 2012, 15, 412-420, doi:10.1016/j.mssp.2012.02.008.

29. Yamazaki, S. New crystalline structure yields reliable thin-film transistors. SPIE Newsroom 2012, 1, 2-4, doi:10.1117/2.1201209.004452.

30. Daus, A.; Vogt, C.; Münzenrieder, N.; Petti, L.; Knobelspies, S.; Cantarella, G.; Luisier, M.; Salvatore, G.A.; Tröster, G. Charge Trapping Mechanism Leading to Sub-60-mV/decade-Swing FETs. IEEE Trans. Electron Devices 2017, 64, 2789-2796, doi:10.1109/TED.2017.2703914.

31. Chen, K.-L.; Jiang, G.-J.; Chang, K.-W.; Chen, J.-H.; Wu, C.-H. Gas sensing properties of indium-gallium-zinc-oxide gas sensors in different light intensity. Anal. Chem. Res. 2015, 4, 8-12, doi:10.1016/j.ancr.2015.03.001.

32. Kang, D.; Lim, H.; Kim, C.; Song, I.; Park, J.; Park, Y.; Chung, J. Amorphous gallium indium zinc oxide thin film transistors: Sensitive to oxygen molecules. Appl. Phys. Lett. 2007, 90, 10-13, doi:10.1063/1.2723543.

33. Sonker, R.K.; Sabhajeet, S.R.; Singh, S.; Yadav, B.C. Synthesis of $\mathrm{ZnO}$ nanopetals and its application as $\mathrm{NO}_{2}$ gas sensor. Mater. Lett. 2015, 152, 189-191, doi:10.1016/j.matlet.2015.03.112.

34. Berkowitz, J.; Chupka, W.A.; Gutman, D. Electron Affinities of $\mathrm{O}_{2}, \mathrm{O}_{3}, \mathrm{NO}, \mathrm{NO}_{2}, \mathrm{~N}_{3}$ by Endothermic Charge Transfer. J. Chem. Phys. 1971, 55, 2733-2745, doi:10.1063/1.1676488.

35. Barsan, N.; Weimar, U. Conduction model of metal oxide gas sensors. J. Electroceram. 2001, 7, 143-167, doi:10.1023/A:1014405811371.

36. Conley, J.F. Instabilities in amorphous oxide semiconductor Thin-Film transistors. IEEE Trans. Device Mater. Reliab. 2010, 10, 460-475, doi:10.1109/TDMR.2010.2069561.

37. Chizhov, A.S.; Rumyantseva, M.N.; Vasiliev, R.B.; Filatova, D.G.; Drozdov, K.A.; Krylov, I.V.; Marchevsky, A.V.; Karakulina, O.M.; Abakumov, A.M.; Gaskov, A.M. Visible light activation of room temperature $\mathrm{NO}_{2}$ gas sensors based on $\mathrm{ZnO}, \mathrm{SnO}_{2}$ and $\mathrm{In}_{2} \mathrm{O}_{3}$ sensitized with CdSe quantum dots. Thin Solid Films 2016, 618, 253-262, doi:10.1016/j.tsf.2016.09.029. 
38. Chung, W.-F.; Chang, T.-C.; Li, H.-W.; Chen, C.-W.; Chen, Y.-C.; Chen, S.-C.; Tseng, T.-Y.; Tai, Y.-H. Influence of $\mathrm{H}_{2} \mathrm{O}$ Dipole on Subthreshold Swing of Amorphous Indium-Gallium-Zinc-Oxide Thin Film Transistors. Electrochem. Solid-State Lett. 2011, 14, H114-H116, doi:10.1149/1.3526097.

39. Fakhri, M.; Johann, H.; Görrn, P.; Riedl, T. Water as origin of hysteresis in zinc tin oxide thin-film transistors. ACS Appl. Mater. Interfaces 2012, 4, 4453-4456, doi:10.1021/am301308y.

40. Kneer, J.; Eberhardt, A.; Walden, P.; Ortiz Pérez, A.; Wöllenstein, J.; Palzer, S. Apparatus to characterize gas sensor response under real-world conditions in the lab. Rev. Sci. Instrum. 2014, 85, doi:10.1063/1.4878717.

(C) 2018 by the authors. Licensee MDPI, Basel, Switzerland. This article is an open access article distributed under the terms and conditions of the Creative Commons Attribution (CC BY) license (http:/ / creativecommons.org/licenses/by/4.0/). 